\title{
Theoretical Studies of Concentrated Aqueous Urea Solutions Using Computacional Monte Carlo Simulation
}

\author{
Celso A. Bertran ${ }^{* a}$, José J. V. Cirino ${ }^{b}$ and Luiz C. G. Freitas ${ }^{c}$ \\ ${ }^{a}$ Instituto de Química, Universidade Estadual de Campinas, CP 6154, 13083-970, Campinas - SP, Brazil \\ ${ }^{b}$ Departamento de Física - ICE, Universidade Federal de Juiz de Fora, 36036-330, Juiz de Fora - MG, Brazil \\ ${ }^{c}$ Departamento de Química, Universidade Federal de São Carlos, CP 676, 13565-905, São Carlos - SP, Brazil
}

\begin{abstract}
Simulações de Monte Carlo foram realizadas para soluções aquosas concentradas de uréia nas concentrações de 4, 5, 6, 7 e $8 \mathrm{~mol} \mathrm{~L}^{-1}$ no ensemble $\mathrm{NpT}$ a $298 \mathrm{~K}$ e $1 \mathrm{~atm}$. As superfícies de energia potencial foram representadas pela soma dos potenciais clássicos de Coulomb e de Lennard-Jones, nos quais a aditividade de pares foi considerada. Nas simulações a água foi descrita pelo modelo TIP4P e a uréia por dois modelos: o modelo OPLS planar e um modelo no qual a molécula de uréia não é totalmente planar. Os resultados das simulações para os dois modelos mostraram que a uréia não causa perturbações significativas na estrutura da água, na faixa de concentrações estudadas. No entanto, foi observada diminuição do número médio de ligações de hidrogênio entre as moléculas de água. Para as soluções mais concentradas os resultados obtidos com o modelo OPLS sugerem a formação de dímeros de uréia. Observou-se similaridade entre alguns dos resultados das simulações obtidos com os modelos: OPLS planar e não-planar da uréia , nas mesmas concentrações e condições.
\end{abstract}

Monte Carlo simulations were carried out for concentrated aqueous urea solutions at 4, 5, 6, 7 and $8 \mathrm{~mol} \mathrm{~L}^{-1}$ in the NpT ensemble at $298 \mathrm{~K}$ and $1 \mathrm{~atm}$. The potential energy surfaces were represented by the sum of Coulomb and Lennard-Jones potentials in which pair-wise additivity was considered. Water was described by the TIP4P model, while urea was described by the OPLS planar model and also by a proposed non-planar model. The simulation results for both urea models showed that urea does not induce any significant changes in the structure of water over all the concentrations studied. However, it was noted that the number of hydrogen bonds between the water molecules decrease as the concentration increases. The simulation results of the OPLS planar model suggest the formation of urea dimers in the more concentrated solutions. The simulations with the non-planar model showed several features similar to those of the OPLS planar model.

Keywords: urea, Monte Carlo, liquid simulation

\section{Introduction}

Urea is a substance that has been studied for many years due to its important physico-chemical properties, especially in concentrated aqueous solutions. Properties such as protein denaturation, ${ }^{1}$ solubility enhancement of hydrocarbons in water, ${ }^{2}$ inhibition of micellar aggregation ${ }^{3}$ and formation of quasi-ideal solutions with water ${ }^{4}$ have been associated with urea in aqueous solution. Recently, urea was reported to play an important role in the homogeneity of some ceramic materials prepared by solgel routes. ${ }^{5-7}$

\footnotetext{
*e-mail: bertran@iqm.unicamp.br
}

Various experimental studies of aqueous urea solutions were published in the last 30 years, trying to establish a model for urea's action in terms of urea-water interactions, but until now, the published results are not in agreement. Frank and Franks, ${ }^{8}$ for instance, pointed out that the hydrogen bonds between water molecules are destroyed. Infrared studies ${ }^{9}$ showed an increase in the intensity of the $\mathrm{O}-\mathrm{H}$ stretching band, which also suggests a weakening of the hydrogen bonds between water molecules as a result of urea addition. On the other hand, Stokes ${ }^{4}$ affirmed that the water structure is essentially unchanged and that urea molecules can form dimers in solution. Raman studies ${ }^{10}$ did not show any evidence of urea dimers in dilute solutions. More recently, Hoccart and Turrell ${ }^{11}$ published an infrared study of aqueous urea solutions. The authors 
concluded that urea does not form dimers in solution, even in more concentrated solutions. They also suggested that the water structure is a result of dipole-dipole interactions instead of hydrogen bonds.

In the field of computational chemistry the theoretical studies of Kuharski and Rossky, ${ }^{12}$ Nakanishi, ${ }^{13}$ Tanaka et al.,${ }^{14}$ Cobos et al. ${ }^{15}$ and Åstrand et al. ${ }^{16}$ showed no influence of urea on the structure of water. These authors suggested that urea was able to enter the structure of water causing little perturbation.

In the present work, Monte Carlo statistical simulations were used to investigate the thermodynamics and structure of aqueous urea solutions over a wide range of concentrations. Two urea molecular geometries were used: a planar one derived from crystallographic determinations on solid urea, and the another one, slightly non planar, as predicted by $a b$ initio calculations.

\section{Computational Details}

\section{Intermolecular potential function}

The potential energy between two molecules $\mathbf{a}$ and $\mathbf{b}$ is described by the sum of the Coulomb and LennardJones potentials,

$$
\begin{aligned}
& E\left(r_{i j}\right)=q_{i} q_{j} / r_{i j}+4 \varepsilon_{i j}\left[\left(\sigma_{i j} / r_{i j}\right)^{12}-\left(\sigma_{i j} / r_{i j}\right)^{6}\right] \\
& E_{a b}=\sum_{i}^{a} \sum_{j}^{b} E\left(r_{i j}\right)
\end{aligned}
$$

where $r_{i j}$ is the distance between site $i$ on molecule a and site $j$ on molecule $\mathbf{b}$, and $q_{k}$ is the partial point charges of the sites. The parameters $\sigma_{i j}$ and $\varepsilon_{i j}$ for non-diagonal interactions were obtained by the same combining rules used by Duffy et al.: ${ }^{17}$

$\varepsilon_{i j}=\left(\varepsilon_{i} \varepsilon_{j}\right)^{1 / 2}$ and $\sigma_{i j}=\left(\sigma_{i} \sigma_{j}\right)^{1 / 2}$

\section{Models for urea}

Two different models for urea molecules were used in this work. The geometry of the first model was obtained from published crystallographic data ${ }^{18}$ and for the other model, the $a b$ initio geometry was calculated at the MP2/ MC-311G(d,p) level. ${ }^{19}$ While the crystallographic data show an essentially planar structure for urea, the $a b$ initio calculation predicts a non-planar structure. ${ }^{19}$

The Lennard-Jones parameters and partial point charges for the planar urea OPLS model were obtained from the work of Duffy et al. ${ }^{17}$ For the non-planar model, the same
Lennard-Jones parameters were used and the point charges were obtained from $a b$ initio calculation with the $\mathrm{CHELPG}^{20}$ procedure. Both models are summarized in Table 1. For water molecules the TIP4P model ${ }^{21}$ was used.

\section{Monte Carlo Simulations}

Thermodynamics and structural properties of concentrated aqueous urea solutions were determined with the use of the Diadorim ${ }^{22}$ program, which employs a Metropolis Monte Carlo method. Periodic boundary conditions in the NpT ensemble were adopted at $298 \mathrm{~K}$ and $1 \mathrm{~atm}$ and the minimal image convention was used. Cubic boxes with 360 molecules were used and the ratio between urea and water molecules was adjusted to reproduce the range of concentrations of interest. According to the Metropolis algorithm, new configurations generated in the simulation procedure should be obtained through translations and rotations of a randomly chosen molecule in the simulation box. The ranges permitted for the translations and rotations for the chosen molecule were set to provide an acceptance of about $40-60 \%$ of all the motions attempted. For urea molecules, the ranges for translations and rotations were set to $0.011 \mathrm{~nm}$ and 11 degrees, respectively. For water molecules the corresponding values were set to $0.015 \mathrm{~nm}$ and 15 degrees.

After every 1000 configurations, one volume change of the box was attempted and the range of volume change was set to $0,180 \mathrm{~nm}^{3}$ to provide the same ratio of acceptance for the new generated configurations. The interactions between any pair of sites were calculated within a cut-off radius of $1.1 \mathrm{~nm}$. No long-range corrections to the Lennard-Jones potential were made beyond the cutoff radius, provided that its contribution to the total intermolecular energy was less than $2 \% .{ }^{23}$ The simulation boxes were equilibrated by the generation of $1 \times 10^{6}$ configurations and for the averaging procedure, $3 \times 10^{6}$ additional configurations were generated.

The error bars of the equilibrium averages are calculated according to the expressions: ${ }^{24}$

$$
\begin{aligned}
& \sigma^{2}(A)=1 / \tau_{\text {run }} \sum_{\tau=1}^{\tau_{\text {run }}}\left(A(\tau)-\langle A\rangle_{\text {run }}\right)^{2} \\
& \langle A\rangle_{\text {run }}=1 / \tau_{\text {run }} \sum_{\tau=1}^{\tau_{\text {run }}} A(\tau)
\end{aligned}
$$

This approach assumes that $A(\tau)$ is a Gaussian function and that $\langle A\rangle_{\text {run }}$ is the average of property $A$ evaluated in simulations of $\tau_{\text {run }}$ configurations in the Monte Carlo method. 


\section{Results and Discussion}

\section{Simulation with OPLS urea model}

The Monte Carlo simulations were carried out in the following concentrations: 4, 5, 6, 7 and $8 \mathrm{~mol} \mathrm{~L}^{-1}$. This range was chosen because an interesting behavior of the experimental density of the urea solutions was noted as a function of the concentration and is illustrated in Figure 1 , where the first derivative is also plotted. The inflexion point near $6 \mathrm{~mol} \mathrm{~L}^{-1}$ may be interpreted as a slight expansion of the whole solution as the concentration is raised from 0 to $6 \mathrm{~mol} \mathrm{~L}^{-1}$. After this point the solutions appear to contract, which suggests that the solution is less densely packed at the concentration of $6 \mathrm{~mol} \mathrm{~L}^{-1}$. This phenomenon may be related to other important properties of aqueous urea solutions.

The Lennard-Jones intermolecular potential parameters of the OPLS urea model, described in Table 1, were obtained from the works of Duffy et $a{ }^{17}$ and Jorgensen and Swenson, ${ }^{25}$ and the geometric data came from a crystal electron diffraction study. ${ }^{18}$

The results for the calculated densities and heats of vaporization $\left(\Delta_{\text {vap }} \mathrm{H}\right)$ of the studied solutions are summarized in Table 2 and are in good agreement with the experimental values. As can be noted, errors are less than $0.4 \%$ for the densities and around $4 \%$ for $\Delta_{\text {vap }} H$. The experimental vaporization enthalpies have been obtained

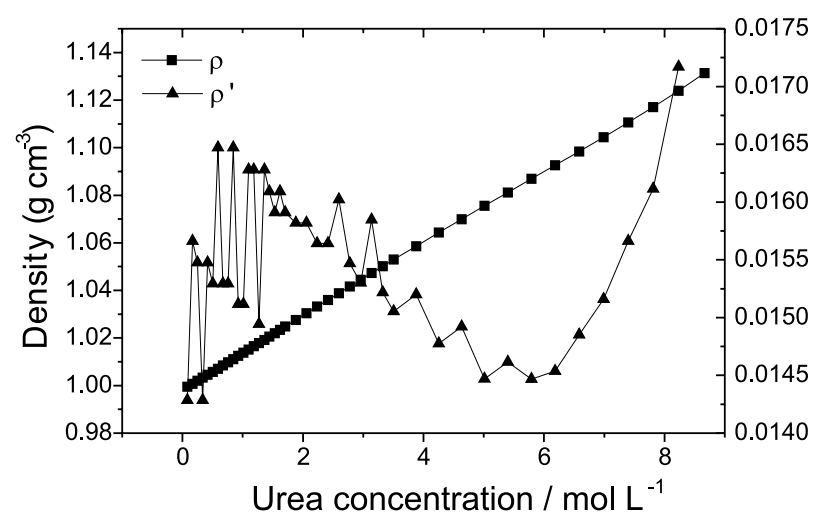

Figure 1. Density of urea solution $s^{27}$ and the first derivative as a function of concentration

Table 1. Point charges and Lennard-Jones parameters for the urea models. LJ parameters are the same for both models

\begin{tabular}{lcccc}
\hline Site & $\mathrm{q}(\mathrm{e})$ & $\mathrm{q}(\mathrm{e})^{*}$ & $\varepsilon\left(\mathrm{kJ} \mathrm{mol}^{-1}\right)$ & $\sigma(\AA)$ \\
\hline $\mathrm{C}$ & 0.142 & 0.963 & 0.439 & 3.75 \\
$\mathrm{O}$ & 0.390 & 0.578 & 0.879 & 2.96 \\
$\mathrm{~N}$ & 0.542 & 1.004 & 0.711 & 3.25 \\
$\mathrm{H}$ & 0.333 & 0.406 & 0.000 & 0.00 \\
\hline
\end{tabular}

*non-planar urea model
Table 2. Calculated densities and heats of vaporization of the OPLS and non-planar urea mixtures

\begin{tabular}{|c|c|c|c|}
\hline \multirow{2}{*}{$\begin{array}{l}\text { [Urea] } \\
\mathrm{mol} \mathrm{L}^{-1}\end{array}$} & \multicolumn{2}{|c|}{ Models } & \multirow[b]{2}{*}{ Experimental } \\
\hline & OPLS & Non-Planar & \\
\hline & \multicolumn{3}{|c|}{ Density $/ \mathrm{g} \mathrm{cm}^{-3}$} \\
\hline 4 & $1.054 \pm 0.001$ & $1.056 \pm 0.002$ & 1.058 \\
\hline 5 & $1.073 \pm 0.002$ & $1.074 \pm 0.002$ & 1.073 \\
\hline 6 & $1.087 \pm 0.003$ & $1.088 \pm 0.002$ & 1.088 \\
\hline 7 & $1.102 \pm 0.003$ & $1.103 \pm 0.002$ & 1.103 \\
\hline 8 & $1.119 \pm 0.003$ & $1.117 \pm 0.002$ & 1.118 \\
\hline & \multicolumn{3}{|c|}{ Heat of Vaporization / $\mathrm{kJ} \mathrm{mol}^{-1}$} \\
\hline 4 & $43.58 \pm 0.05$ & $42.26 \pm 0.05$ & 43.85 \\
\hline 5 & $44.09 \pm 0.05$ & $44.61 \pm 0.07$ & 43.60 \\
\hline 6 & $43.49 \pm 0.11$ & $45.18 \pm 0.06$ & 43.52 \\
\hline 7 & $43.63 \pm 0.09$ & $46.75 \pm 0.06$ & 43.61 \\
\hline 8 & $42.50 \pm 0.10$ & $46.92 \pm 0.06$ & 43.86 \\
\hline
\end{tabular}

from vapor pressure data ${ }^{25}$ and the densities of urea solutions at $298 \mathrm{~K}$ were taken from reference 26.

Although the OLPS urea model was optimized to reproduce the experimental densities and heats of vaporization of dilute urea solutions, these properties were well reproduced for urea solutions at high concentrations as well as was the behavior of the derivative of the density plot (not shown).

The average interaction energies of urea-urea $\left(E_{u u}\right)$, urea-water $\left(E_{u w}\right)$, water-water $\left(E_{w w}\right)$ and the total energy are plotted in Figure 2. This energy partition is a consequence of the adopted pair additivity approximation, which is represented in equation 6 :

$E_{T}=E_{u u}+E_{u w}+E_{w w}$

The energies $E_{u u}, E_{u w}$, and $E_{w w}$ show a similar behavior to the interaction energies in a quasi-ideal mixture, that change almost linearly with the molar fraction.

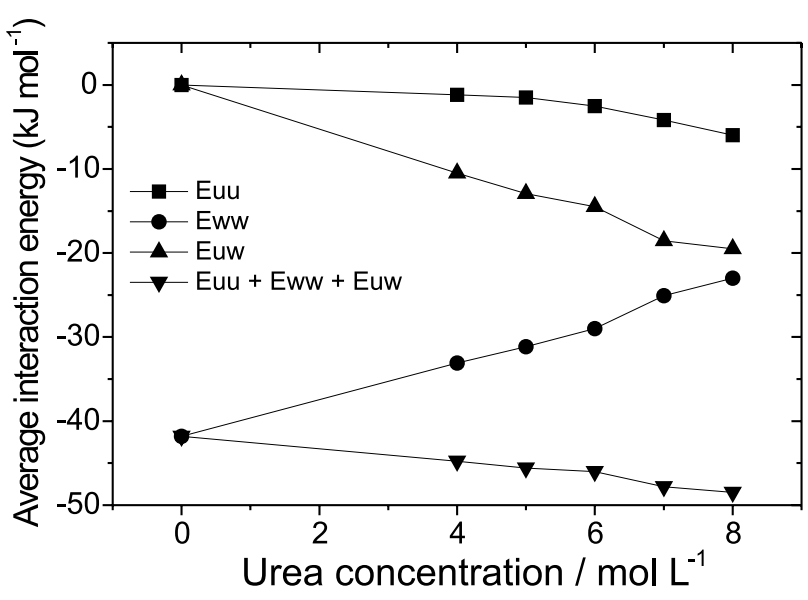

Figure 2. OPLS average configurational energies, in $\mathrm{kJ} \mathrm{mol}^{-1}$, of the urea + water mixtures 
The contribution of $E_{u u}$ to the total energy $\left(E_{T}\right)$ is very small in the range of concentrations studied, when compared to $E_{u w}$ and $E_{w w}$. $E_{u u}$ represents only about $3 \%$ of the total energy in the least concentrated solution and its contribution to $E_{T}$ increases almost linearly until the most concentrated one. The interaction energy between water molecules is lowered as the solution becomes more concentrated. In the most concentrated solution we observe that $E_{u w}$ is almost equal to $E_{w w}$ suggesting that urea molecules interact with water in almost the same manner as water molecules with other water molecules.

The possible influence of urea on the local water structure can be verified by comparing the radial distribution function (rdf) of pure water to that of the water in urea solutions. The comparison between $g_{O_{w} O_{w}}(r)$ and $g_{O_{w H w}}(r)$ is shown in Figure 3. The first peaks in the plots of $g_{O_{w O W}}(r)$ in Figure 3a show a strong correlation between oxygen atoms near $0.28 \mathrm{~nm}$. Its shape and position are practically unaffected as the urea concentration is changed. The variation of the concentration of urea only causes a small change in the intensity of the peaks of $g(r)$.

The radial distribution functions are defined by equation 7 that shows an inverse dependence of $g(r)$ with $r_{j}$, the numerical density of sites $j .{ }^{24}$

$$
g_{i j}(r)=\frac{N_{i j}(r, r+\Delta r)}{4 \pi r^{2} \Delta r \rho_{j}}
$$

When urea is added to obtain more concentrated solutions, $r_{j}$ is slightly lowered resulting in an increase of the intensities of peaks in the rdf of water.

The integration of $g_{O w O w}(r)$ from 0 to the first minimum of the non-normalized $\mathrm{g}(\mathrm{r})$ functions, shown in Figure 3a, results in the average number of water molecules in its first hydration shell. For pure water it is almost equal to 5 and for the urea + water mixtures, this number is 4 , as is shown in Table 3.

The second peak of the rdf plots, shown in Figure 3a, is correlated with the second hydration shell of water. Only a limited change in the position of this peak was observed, which suggests that urea addition in this concentration range does not disturb the tetrahedral structure of water.

Figure $3 \mathrm{~b}$ shows the $g_{\text {OwHw }}(r)$ rdf, which is correlated with the hydrogen bonds between water molecules. As observed in the previous case, the peaks maintain their shape and positions and are almost invariant from pure water to the most concentrated solution. However, the integration of $g_{\text {OwHw }}(r)$ shown in Table 3 indicates significant reduction of
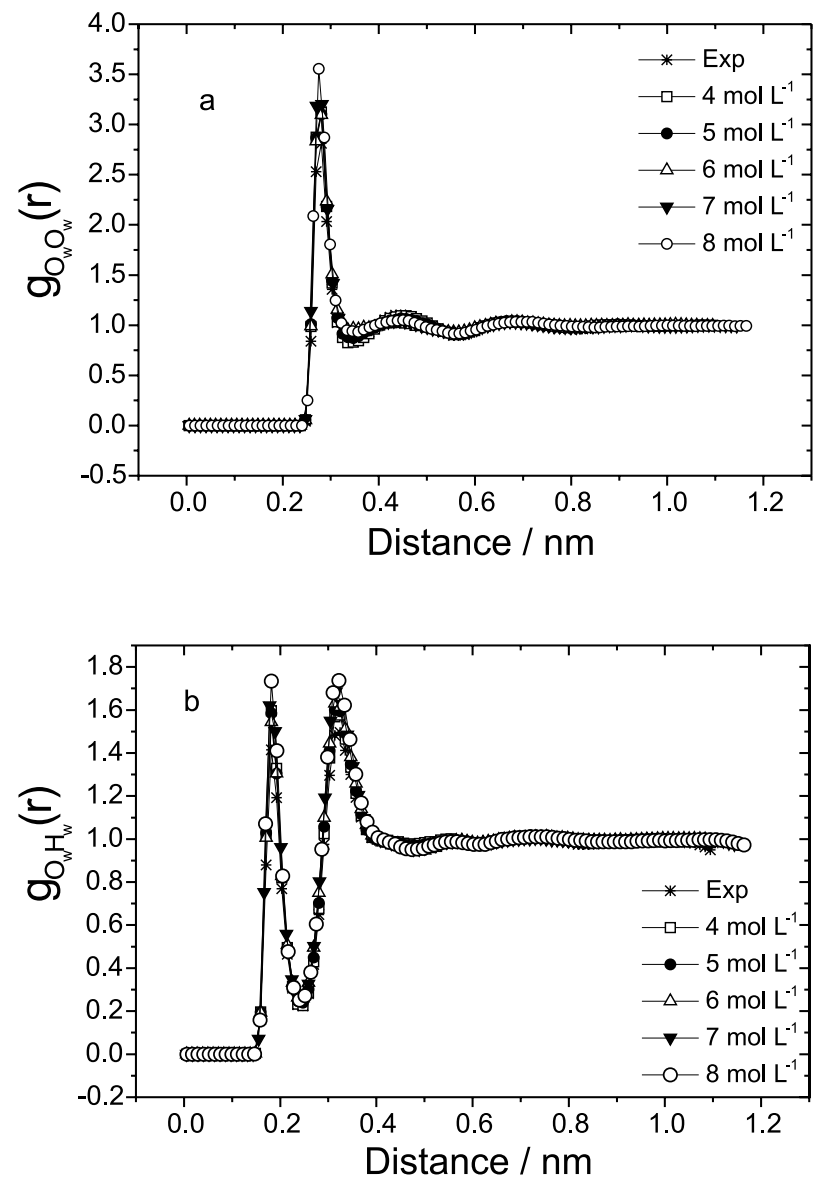

Figure 3. Experimental radial distribution functions of pure water and OPLS calculated radial distribution function of the water in the urea + water mixtures. a) $g_{O w O w}(r)$, b) $g_{O w H w}(r)$

Table 3. Coordination numbers (n) between urea OPLS and water sites obtained from integration of the first peaks of the radial distribution functions

\begin{tabular}{ccccccccc}
\hline [Urea]* & $\mathrm{n}_{\text {OuHu }}$ & $\mathrm{n}_{\text {CuCu }}$ & $\mathrm{n}_{\text {OuHw }}$ & $\mathrm{n}_{\text {CuOw }}$ & $\mathrm{n}_{\text {HuOw }}$ & $\mathrm{n}_{\text {OwOw }}$ & $\mathrm{n}_{\text {OwHw }}$ & $\mathrm{N}$ \\
\hline 0 & 0.0 & 0.0 & 0.0 & 0.0 & 0.0 & 4.8 & 4.0 & 0.0 \\
4 & 0.5 & 2.2 & 2.3 & 15.2 & 2.8 & 4.2 & 1.8 & 5.1 \\
5 & 0.5 & 2.5 & 2.3 & 18.0 & 2.8 & 4.1 & 1.7 & 5.1 \\
6 & 0.6 & 3.1 & 2.4 & 16.7 & 2.7 & 4.1 & 1.5 & 5.1 \\
7 & 0.8 & 4.2 & 2.0 & 16.1 & 2.4 & 3.9 & 1.6 & 4.4 \\
8 & 1.0 & 5.0 & 1.9 & 16.9 & 2.4 & 3.7 & 1.4 & 4.3 \\
\hline
\end{tabular}

*mol $\mathrm{L}^{-1} \quad \mathrm{~N}$ is the total number of urea-water hydrogen bonds 
the number of hydrogen bonds between water molecules, in agreement with experimental data. ${ }^{8}$

The results of $g_{O w H w}(r) \mathrm{rdf}$ and the integration of the first peak indicate that the addition of urea does not cause a significant perturbation in the water structure, although $50 \%$ of the water hydrogen bonds were broken. This conclusion, that the water structure in not disturbed when half of the hydrogen bonds are broken, is apparently contradictory. However, Hoccart and Turrell ${ }^{11}$ suggested that the water structure could be maintained by dipoledipole interactions.

Figure 4 shows the radial distribution functions $g_{\mathrm{CuCu}}(r)$ and $g_{\text {OuHu}}(r)$ for urea molecules. The first peak of the $g_{\text {OuHu }}(r)$ plots, shown in Figure 4b, indicates that hydrogen bonds between urea molecules are centered at about $0.20 \mathrm{~nm}$ and the first peak of the $g_{C u C u}(r)$, in Figure $4 \mathrm{a}$, shows that the average distance between these sites (located near the center of mass of the molecule and correlated with the distribution of urea molecules around a reference urea molecule) is about $0.45 \mathrm{~nm}$ and does not change with concentration.
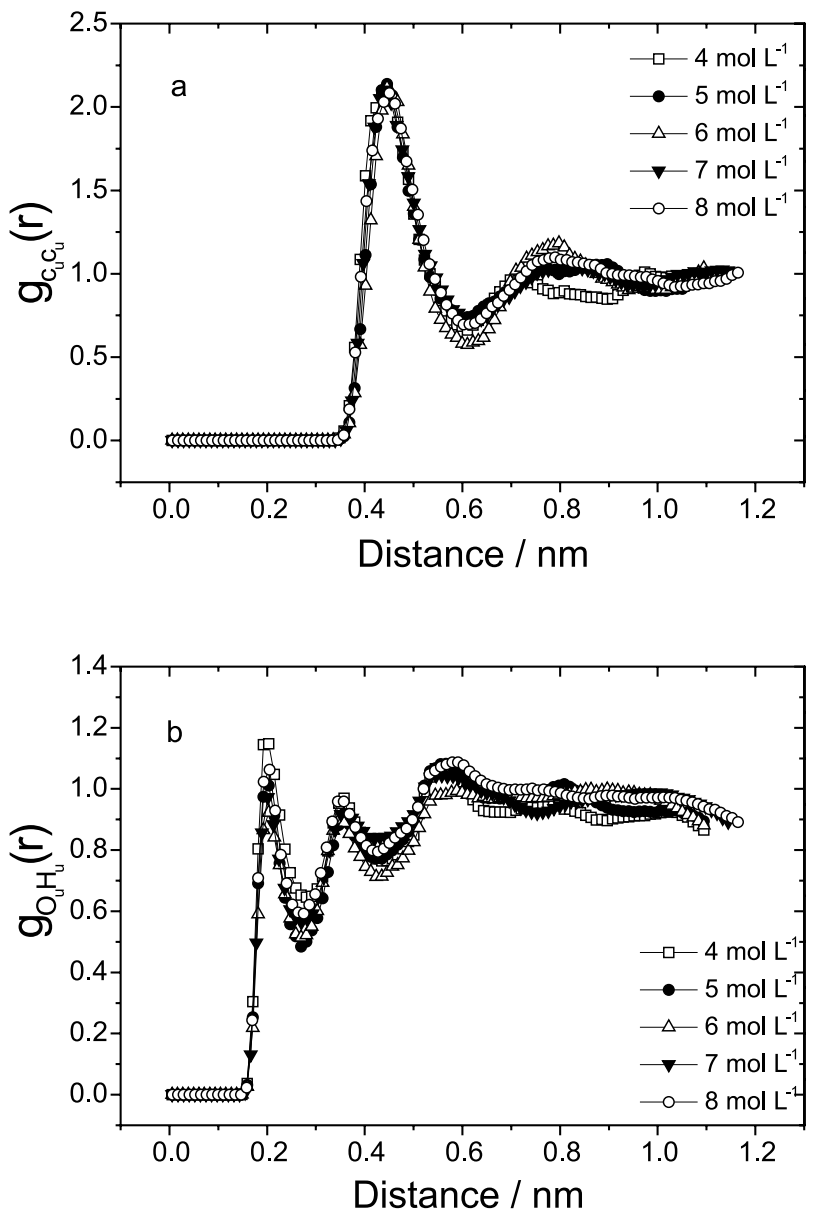

Figure 4. OPLS calculated radial distribution functions of urea molecules in the urea + water mixtures. a) $g_{\mathrm{CuCu}}(r)$, b) $g_{\mathrm{OuHu}}(r)$
The integration of the first peaks in Figures $4 \mathrm{~b}$ and $4 \mathrm{a}$ gives the average number of hydrogen bonds between urea molecules and the average number of urea molecules around a reference urea molecule, as given in Table 3 . The increase of the average number of hydrogen bonds and the average number of neighbors can be explained by the tendency of urea to form dimers as the concentration is raised. The energetics of urea-urea interactions, shown in Figure 2, support the conclusions based on the radial distribution functions. This result is in agreement with the experimental observations of Stokes ${ }^{4}$ and other theoretical investigations, ${ }^{15,16}$ but it is contrary to other experimental studies. ${ }^{10,11}$

Figures 5a and 5b show the $g_{O u H w}(r)$ and $g_{H u O w}(r)$ radial distribution functions between urea and water sites. The results of the integration $\left(\mathrm{n}_{\mathrm{OuHw}}\right.$ and $\left.\mathrm{n}_{\mathrm{HuOw}}\right)$ of these rdf (Table 3) show that urea forms hydrogen bonds with water and the average number of these bonds is about 5 in the most dilute solutions, in good agreement with the work of Duffy et al. ${ }^{17}$ Although the first peak of the $g_{H u O w}(r) \operatorname{rdf}$ is less than unity, the integration shows that there are hydrogen bonds in this site of urea.
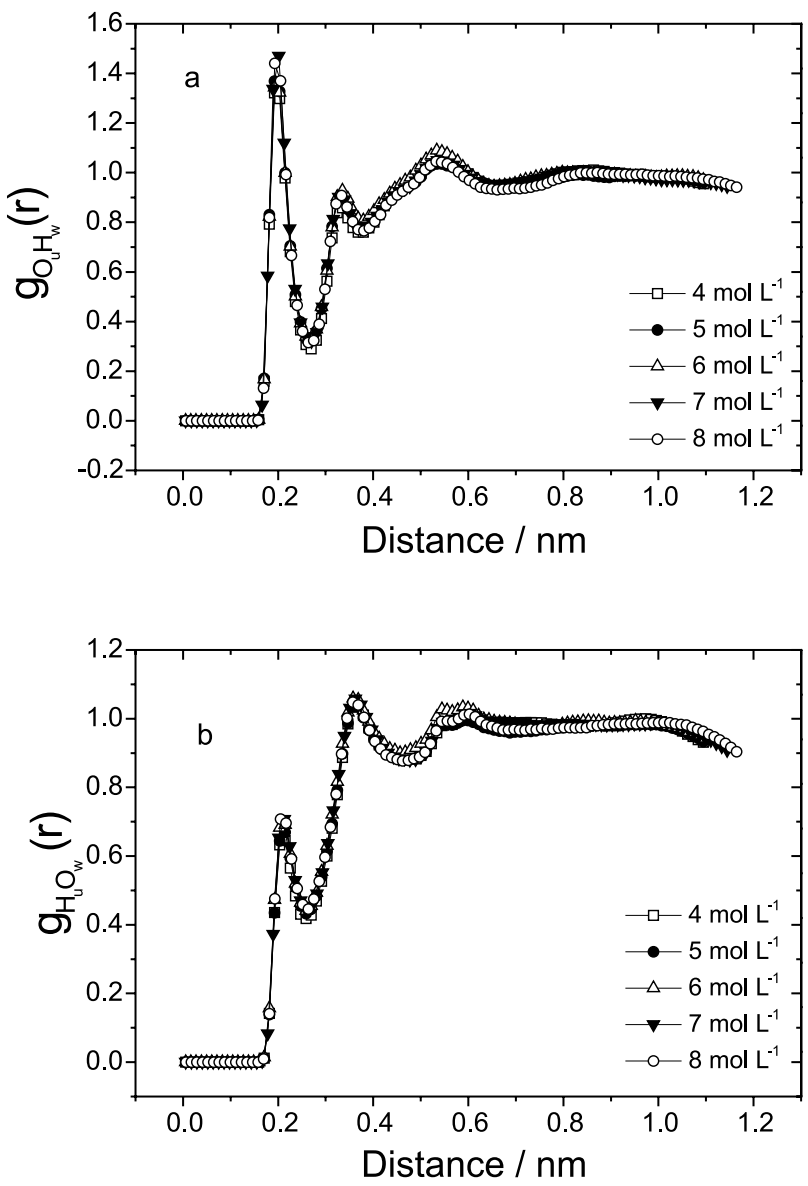

Figure 5. OPLS calculated radial distribution functions between urea and water molecules in the urea + water mixtures. a) $g_{\text {OuHw }}(r)$, b) $g_{\text {HuOw }}(r)$ 
The average distance between the centers of mass of urea and water, indicated by the $g_{C u O w}(r)$ rdf in Figure 6, is about $0.4 \mathrm{~nm}$. The corresponding peak of the $6 \mathrm{~mol} \mathrm{~L}^{-1}$ solution is broader than the others, indicating that, at this concentration, the water molecules are, on the average, more distant from urea molecules, characterizing a less densely packed solution, in very good agreement with the behavior of the experimental and calculated densities shown in Figure 1.

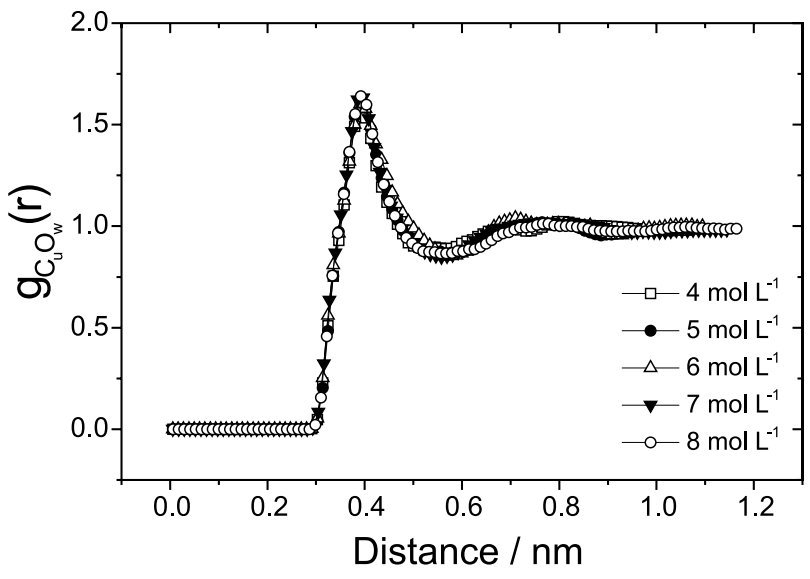

Figure 6. OPLS calculated radial distribution functions between urea and water molecules in the urea + water mixtures. $g_{\mathrm{CuOw}}(r)$

\section{Simulation with non-planar urea model}

In this section, we studied a proposed model for urea in which the hydrogen atoms are out of the plane of the heavy atoms, with dihedral angles of cis and trans hydrogen atoms of about 13 and 150 degrees, respectively. ${ }^{19}$ The same concentrations of the previous urea model were used, as well as the Monte Carlo simulation conditions. The intermolecular Lennard-Jones potential parameters were transferred from the planar urea model and the charges were derived from electrostatic potential grid ${ }^{20}$ (CHELPG) calculations using the software Gaussian 94. ${ }^{29}$ The nonplanar urea model, described in Table 1, has a lower dipole moment (3.2 D) than either the OPLS model (4.9 D) or the experimental value $(5.7 \mathrm{D}){ }^{30}$

The calculated densities and vaporization enthalpies for non-planar urea solutions are shown in Table 2. The results for densities are very good, but we obtained some large deviations in the calculations of the enthalpy of vaporization. In this non-planar model, the less densely packed effect of the $6 \mathrm{~mol} \mathrm{~L}^{-1}$ solution was not observed.

The partition of the total configurational energy was also analyzed in this model of urea by the pair-wise additivity approximation. The total average configurational energy $\left(E_{T}\right)$ and the contribution of the individual pair interaction energies of urea-urea $\left(E_{u u}\right)$, urea-water $\left(E_{u w}\right)$ and water-water $\left(E_{w w}\right)$ to $E_{T}$ show a similar behavior of these partial interaction energies as does the OPLS urea model. Thus, non-planar urea aqueous solutions are also quasiideal solutions.

The similarity observed for the interaction energies between the OPLS and the non-planar models was also observed for the $g_{O w O w}(r)$ and $g_{O w H w}(r)$ rdf, for the average number of water molecules in its first hydration shell and for the same significant reduction of the number of hydrogen bonds between water molecules.

Figures $7 \mathrm{a}$ and $7 \mathrm{~b}$ present the $g_{\text {CuCu}}(r)$ and $g_{\text {OuHu }}(r)$ rdf for non-planar urea sites, where the most significant differences between the non-planar and OPLS urea models are noted . In the non-planar urea model, there is essentially no interaction between urea molecules. The integration of the first peak of $g_{\text {Outu }}(r)$ rdf shows that the average number of hydrogen bonds $\left(\mathrm{n}_{\mathrm{OuHu}}\right)$ is 0.1 in the concentration range studied.

The first peak of $g_{C u C u}(r)$ shows some splitting that is not to be expected and may be due to the small basis set used to optimize the intermolecular potential.
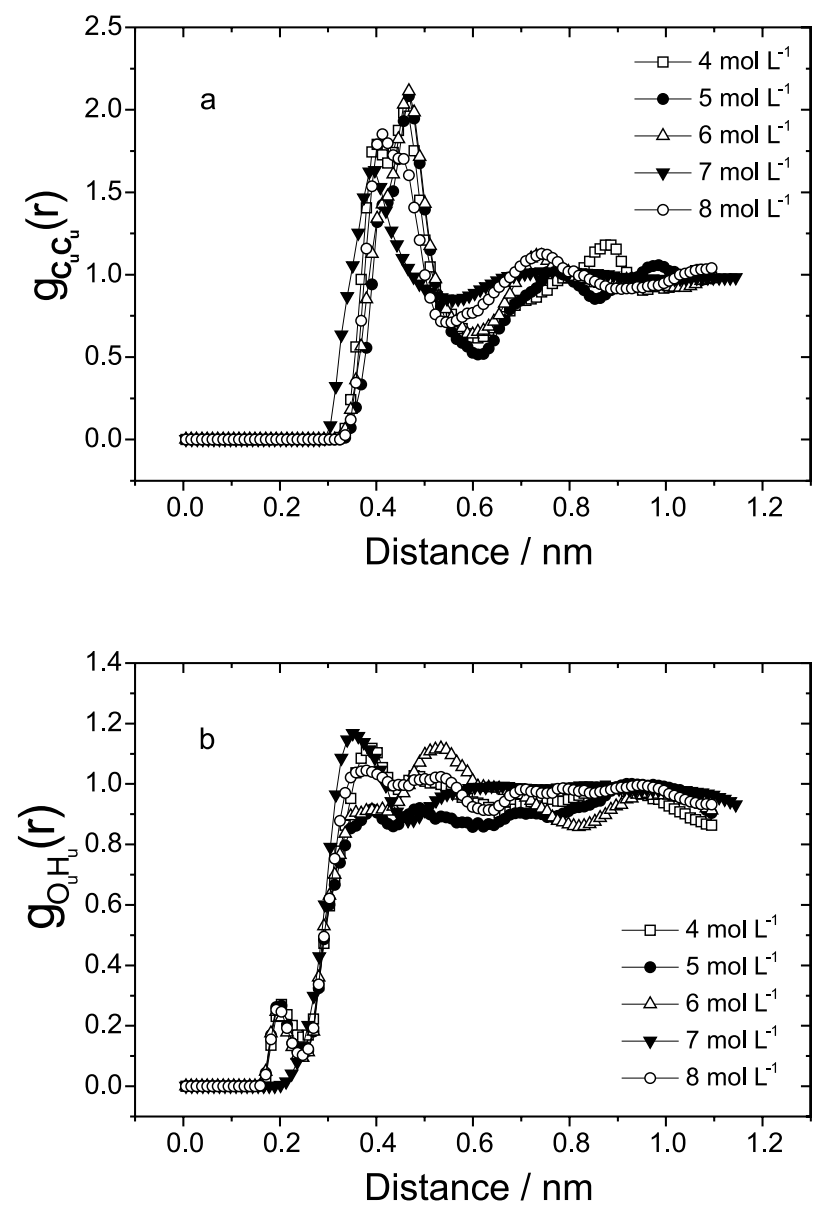

Figure 7. Non-planar calculated radial distribution functions of urea molecules in the urea + water mixtures. a) $g_{\mathrm{CuCu}}(r)$, b) $g_{\text {OuHu }}(r)$ 
The integration of the first peak of the radial distribution functions $g_{\mathrm{OuHw}}(r)$ and $g_{\mathrm{HuOw}}(r)$ results in 3 hydrogen bonds between urea and water while there are 5 hydrogen bonds in the OPLS urea model. The difference of the dipole moment between the two urea models may be the cause for the reduction in the number of hydrogen bonds.

\section{Conclusions}

Thermodynamic and structural results from liquid state simulations showed that urea has a tendency to form dimers when the concentration of the solutions is above $6 \mathrm{~mol} \mathrm{~L}^{-1}$. Moreover, its aqueous solutions exhibit a quasi-ideal solution behavior in the range of concentrations studied. No significant perturbations of the water structure were evident from the data of the radial distribution functions, even in a mixture with a concentration of $8 \mathrm{~mol} \mathrm{~L}^{-1}$. The number of hydrogen bonds between water molecules was observed to decrease with the addition of urea; however, the whole structure of water was kept unchanged. Most of the results of the simulations for the non-planar urea solutions were similar to those of the OPLS urea model simulations. There is a difference in the description of the interaction between two urea molecules that was not well described by the intermolecular potential used, which is presumably due to the basis set chosen to minimize the structure and to calculate the charge distributions over the atoms.

The results of the simulation with the two urea molecule models show that urea does not disturb the structure of water, even in a highly concentrated solution. Urea appears to enter the water structure as if it was a large water molecule.

\section{Acknowledgements}

The authors are grateful for financial support from CNPq (Conselho Nacional de Desenvolvimento Científico e Tecnológico ) and FAPEMIG (Fundação de Amparo à Pesquisa do Estado de Minas Gerais).

\section{References}

1. Brandts, J. F.; Hunts, L. J.; J. Am. Chem. Soc. 1967, 89, 4826.

2. Wetlaufer, D. B.; Malik, S. K.; Stoller, L.; Coffin, R. I.; J. Am. Chem. Soc. 1964, 86, 508.

3. Shick, M. J.; J. Phys. Chem. 1964, 68, 3585.

4. Stokes, R. H.; Aust. J. Chem. 1967, 20, 2087.

5. Bertran, C. A.; Macedo, M. I. F.; Oliveira, M. A. S.; Thim, G. P.; J. Eur. Ceramic Soc. 2001, 21, 759.

6. Bertran, C. A.; Thim, G. P.; Lima, P. T.; An. Ass. Bras. Quim. 1996, 45, 142.

7. Lima, P. T.;Bertran, C. A.; Quim. Nova 1998, 21, 608.
8. Frank, H. S.; Franks, F. J.; J. Chem. Phys. 1968, 48, 4768.

9. Holtzen, A.; Emerson, M. F.; J. Phys. Chem. 1969, 73, 26.

10.Hoccart, X.; Turrell, G.; J. Chem. Phys. 1993, 99, 8498.

11. Hoccart, X.; Turrell, G.; J. Mol. Struct. 1995, 349, 41.

12. Kuharski, R. A.; Rossky, P. J.; J. Am. Chem. Soc. 1984, 106 , 5786.

13. Nakanishi, K.; Chem. Soc. Rev. 1993, 177.

14. Tanaka, H.; Touhara, H.; Nakanishi, K.; Watanabe, N.; J. Chem. Phys. 1984, 80, 5170.

15. Tanaka, H.; Nakanishi, K.; Touhara, H.; J. Chem. Phys. 1984, 82, 5184; Hernández-Cobos, J.; Ortega-Blake, I.; BonillaMarín, M.; Moreno-Bello, M.; J. Chem. Phys. 1993, 99, 9122.

16. Åstrand, P. O.; Wallqvist, A.; Karlstrom, G.; Linse, P.; J. Chem. Phys. 1991, 95, 8419.

17. Duffy, E. M.; Severance, D. L.; Jorgensen, W. L.; Isr. J. Chem. 1993, 33, 323

18. Swaminathan, S.; Craven, B. M.; McMullan, R. K.; Acta Cryst. $B$ 1984, B40, 300

19. Cirino, J. J. V.: PhD Thesis, Universidade Estadual de Campinas, Brazil, 1999

20. Brenneman, C. M.; Wiberg, K. B.; J. Comput. Chem. 1990, $11,361$.

21. Jorgensen, W. L.; J. Chem. Phys. 1979, 71, 5034.

22. Freitas, L. C. G.; Programa Diadorim, Universidade Federal de São Carlos, Brazil, 1992.

23. Freitas, L. C. G.; Cordeiro, J. M. M.; Garbujo, F. L. L.; J. Mol. Liq. 1999, 79,1.

24. Allen, M. P.; Tildesley, D. J.; Computer Simulation of Liquids, Oxford: London, 1987, p. 191.

25. Jorgensen, W. L.; Swenson, C. J.; J. Am. Chem. Soc. 1985, 107, 569.

26. Perman, E. P.; Lovett, T.; Trans. Faraday Soc. 1926, 22, 1.

27. Egan Jr., E. P.; Luff, B. B.; J. Chem. Eng. Data 1966, 11, 192.

28. West, R. C., ed.; Handbook of Chemistry and Physics, $58^{\text {th }}$ ed., CRC Press: New York, 1978.

29. Frisch, M. J.; Trucks, G. W.; Schlegel, H. B.; Gill, P. M. W.; Johnson, B. G.; Robb, M. A.; Cheeseman, T. K.; Petersson, G. A.; Montgomery, J. A.; Raghavachari, K.; Al-Laham, M. A.; Zakrzewski, V. G.; Ortiz, J. V.; Foresman, J. B.; Cioslowski, J.; Stefanov, B. B.; Nanayakkara, A.; Challacombe, M.; Peng, C. Y.; Ayala, P. Y.; Chen, W.; Wong, M. W.; Andres, J. L.; Replogle, E. S.; Gomperts, R.; Martin, R. L.; Fox, D. J.; Binkley, J. S.; Defrees, D. J.; Baker, J.; Stewart, J. J. P.; Head-Gordon, M.; Gonzalez, C.; Pople, J. A.; Gaussian 94, Revision D.2, Gaussian, Inc, 1995.

30. Gaumann, T.; Helv. Chim. Acta 1958, 41B, 1965.

Received: January 3, 2001 Published on the web: March 18, 2002

FAPESP helped in meeting the publication costs of this article. 